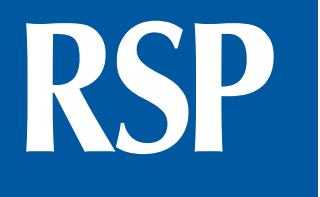

http://www.rsp.fsp.usp.br/

Revista de Saúde Pública

\title{
Prevalence and risk factors of inadequate medicine home storage: a community-based study
}

Rand Randall Martins', Andreza Duarte Farias", Yonara Monique da Costa Oliveira", Rodrigo dos Santos Diniz', Antonio Gouveia Oliveira'

I Universidade Federal do Rio Grande do Norte. Faculdade de Farmácia. Departamento de Farmácia. Natal, RN, Brasil

" Universidade Federal de Campina Grande. Unidade de Saúde, Centro de Educação e Saúde. Cuité, PB, Brasil

\section{ABSTRACT}

OBJECTIVE: Assess the extent of inadequate home storage of medicines andidentify important risk factors.

METHODS: A cross-sectional survey based on a probability sample in the community, conducted in 267 households in Cuité, State of Paraíba, Northeast Brazil, in 2014. Logistic regression was used to study the risk factors.

RESULTS: The prevalence of households with inadequate storage was $76.0 \%$. Problems with storage include direct exposure to sunlight in $10.9 \%$ of households, the presence of dust in $23.6 \%$, and storage within reach of children in $76.0 \%$. Medications no longer used are usually disposed of into the environment in $92.1 \%$ of households. Inadequate storage is more likely when home organization of medications is the responsibility of a male subject $(\mathrm{OR}=1.729)$ or an older person $(\mathrm{OR}=1.029)$, when out of date medicines are found $(\mathrm{OR}=2.963)$, and in households with no children $(\mathrm{OR}=2.088)$.

CONCLUSIONS: Physicians and pharmacists should advise patients on how to adequately store medicines at home, especially when the person in charge of medications is a male or an older adult, and if there are no children in the household.

DESCRIPTORS: Patient Medication Knowledge. Health Knowledge, Attitudes, Practice. Drug Utilization. Drug Storage. Patient Education as Topic. Drug Information Services.

Av. General Gustavo Cordeiro de

Farias, s/n Petrópolis

59012-570 Natal, RN, Brasil

E-mail: randmartins@yahoo.com.br

Received: May 31, 2016

Approved: Nov 3, 2016

How to cite: Martins RR, Farias AD, Oliveira YMC, Diniz RS, Oliveira AG. Prevalence and risk factors of inadequate medicine home storage: a community-based study. Rev Saude Publica. 2017;51:95.

Copyright: This is an open-access article distributed under the terms of the Creative Commons Attribution License, which permits unrestricted use, distribution, and reproduction in any medium, provided that the original author and source are credited. 


\section{INTRODUCTION}

Home storage of medications is a common practice around the world and includes both prescription medicines and over-the-counter (OTC) medications indicated for acute and chronic conditions ${ }^{1,2}$. In recent years, medicine consumption patterns have changed, resulting in larger purchasing volumes and, consequently, excessive amounts stored at home ${ }^{1}$.

In addition to the higher costs ${ }^{2}$, the accumulation of medications at home may be associated with harm to the patients, to their family, and even to the environment. An association between the accumulation of medications and multiple storage locations at home, and unfavorable clinical outcomes or decreased adherence to treatment has been described ${ }^{3}$. This negative association is more likely to be harmful to older adults, who frequently have multiple diseases and a greater number of medications at home, leading to a higher frequency of administration errors, medication interactions, and adverse reactions ${ }^{4}$. A large quantity of medicines in the household has also been implicated in an increased risk of inappropriate self-medication, especially through the administrations of leftover medicines, including nonsteroidal anti-inflammatory medications, corticosteroids, opioids, and antimicrobials ${ }^{1}$. Regarding the latter medications, they are often found in households, representing a potential public health problem due to the risk of the development of multidrug-resistant organisms ${ }^{5}$ tahnks to improper disposal. In many countries, non-existent public regulations for the proper disposal of medications results in the widespread use of the domestic waste and the public sewage system for that purpose, leading to extensive environmental contamination ${ }^{6,7}$. Consequently, it is important to conduct research within the community to understand the prevailing practices of home storage and disposal of medicinal products. This knowledge is important to health professionals, as it may provide guidance for their advice to patients regarding adequate home storage and proper disposal of medications, decreasing the untoward accumulation of medications in the household and its consequent non-rational use. In addition to the risks related to the accumulation of medications already mentioned, the inadequate storage of medications can cause changes in their pharmacological characteristics $^{6,89}$ and lead to accidental poisoning ${ }^{10,11}$.

However, despite the relevance and the serious implications for public health of this subject, studies addressing this issue are scarce and have adopted heterogeneous methodologies and definitions. The problem is complex because the home storage of medicines is influenced by multiple factors, including cultural factors ${ }^{12}$, making it difficult to compare studies originating from different countries. Some studies have investigated the home storage of medications by direct interviews at the time of acquisition in community pharmacies ${ }^{13,14}$ or via telephone surveys ${ }^{15,16}$. Other studies have analyzed medicines collected during campaigns for medications disposal to infer how the medications had been previously stored at home ${ }^{6}$. These approaches have the drawback of failing to observe the actual storage locations and the involved medications, in addition to being susceptible to recall bias and the underreporting of sensitive issues, such as storage of medications within reach of children and medications past the expiration date. Studies that directly inspected the storage locations and the types of stored medications often have small sample sizes, ${ }^{17}$ the home visit was previously scheduled, leading to possible interference in the veracity of the interview ${ }^{1}$, or the data analysis was limited to simple descriptions ${ }^{14,17-20}$.

The objectives of the present study were to assess, in a population-based sample and through a household survey with direct inspection of storage locations, the prevalence of medicine home storage, the extent of inadequate home storage, the methods of medicine disposal, and the identification of inadequate storage risk factors.

\section{METHODS}

This cross-sectional, observational survey was conducted in Cuité, a community of about 20,000 inhabitants located in the State of Paraíba, in Northeastern Brazil, between May and 
June 2014. A stratified proportional random sample was obtained from the 12 census strata in which the town is divided. In each stratum, one street was randomly selected and the house with the lowest home address number was the first to be visited. From there, the home visits followed a strict order: the second house from the left, then the house across the street. This sequence was repeated until the predefined number of adults for that stratum was interviewed.

The studied population consisted of subjects older than 18 years-old, of either gender, who were the persons in charge for the acquisition and storage of medicines in each household. The interview was conducted by a trained and supervised member of staff, and the data were recorded in structured data collection forms. The subjects who declined to allow observation of the medications storage site were not included.

The subjects were questioned regarding age, gender, income, education, number of residents in the household, and number of children under 12 years old. During the interview, medication storage locations were directly inspected and all the medications found in the household were recorded. The storage location was characterized with respect to which room of the house it was located in, the temperature in Fahrenheit, relative humidity, the presence of pollutants (food particles and other organic materials), height from the ground (being considered out of reach of children when above $170 \mathrm{~cm}$ ), and whether the medications were kept in a container with a lid used exclusively for medicines ("home pharmacy"). Data collection was always performed at the same time of the day, between 3 p.m. and 6 p.m. Home storage was considered inadequate when at least one of these characteristics was observed: medications within reach of children, medicines not stored in recipients meant exclusively for this purpose, the presence of pollutants, and humidity. Regulatory agencies and medical societies are emphatic regarding the need to keep medicines out of reach of children and locked in cabinets where medications can be organized and protected from heat, humidity, light, and dust ${ }^{22,23}$. In our study, we followed these guidelines to define the criteria of adequate medicine home storage. The medications were classified by Anatomical Therapeutic Chemical Code (ATC) and pharmaceutical form and checked for the expiration date, utilization in the previous seven days, and presence of proper packaging. The usual method of medication disposal in the household was also recorded. The pilot study was conducted in 10 households located in a different region of the main data collection. During the data collection in the household, interviewers were supervised by the authors. With the pilot study, it was possible to detect problems in the questionnaire, calculate the time of the interview and evaluate the performance of interviewers. However, the validation of the data collection tool was not performed.

A sample size of 270 households was calculated to afford a maximum estimate error of six percentage points with $95 \%$ confidence intervals. Statistical analysis was performed using Stata software release 12 (Stata Corporation, College Station, TX, USA). For the descriptive analysis, demographic, clinical, and economic variables were presented as absolute and relative frequencies or as means and standard deviations, as appropriate. For population estimates, exact (binomial) confidence intervals are presented. Univariate logistic regression analyses were performed to identify variables associated with inappropriate medication storage, and odds ratios and their $95 \%$ confidence intervals are reported. Variables associated with inappropriate medication storage at the $\mathrm{p}<0.10$ significance level in the univariate analysis were included in a multivariate logistic regression model and significant associations were considered if $\mathrm{p}<0.05$.

The study was approved by the Research Ethics Committee of the Hospital Universitário Alcides Carneiro, Universidade Federal de Campina Grande (CAAE 03361212.2.0000.5182).

\section{RESULTS}

In this study, we evaluated 267 households. The mean age of those responsible for medication acquisition and storage was $54.9(\mathrm{SD}=19.2)$ years, $190(71.2 \%)$ of them were females and most 
(62.2\%) had only elementary school education or less. There was an average of 3.3 (SD = 1.4) residents per household, $35.2 \%$ had children, and the monthly income per household was $1.7(\mathrm{SD}=0.9)$ minimum wages $(\mathrm{MW})$.

A total of 803 medications were observed in the 267 households, with an average of 3.7 $(\mathrm{SD}=2.1)$ medications per household. The predominant medicines were cardiovascular medications $(28.7 \%)$, followed by central nervous system medications $(21.8 \%)$, and gastrointestinal tract and metabolism medications (16.7\%). There was a predominance of solid and semi-solid pharmaceutical forms $(77.2 \%)$. Most medications had no secondary packaging $(66.8 \%)$ and $38.4 \%$ had not been used in the previous seven days. There were few medicines past their expiration date $(19,2.4 \%)$. Table 1 summarizes these data.

The prevalence of households with inadequate storage was 76.0\% (95\%CI 70.5-81.0). Direct exposure to sunlight was observed in 29 households (10.9\%, 95\%CI 7.4-15.2) and the presence of pollutants in $63(23.6 \%, 95 \%$ CI 18.6-29.1). Medications were often stored within the reach of children, as was observed in 76.0\% (95\%CI 70.5-81.0) of households. The average temperature and relative humidity in the storage location were $86.7^{\circ} \mathrm{F}\left(\mathrm{SD}=36.1\right.$; equivalent to $30.4^{\circ} \mathrm{C}$ $[\mathrm{SD}=2.3]$ ) and $50.4 \%(\mathrm{SD}=7.3)$, respectively. The house room most often used for storage of medicines was the kitchen $(52.9 \%$, 95\%CI 49.5-56.5), followed by the bedroom (33.2\%; 95\%CI 30.0-36.7). The most common method of medicine disposal was into the environment, either through the household waste or into the public sewerage system (92.1\%, 95\%CI 88.2-95.1). Table 2 summarizes these data.

Univariate logistic regression analyses (Table 3) showed that the inadequate storage of medications is more frequent when the organizer of home medicines is older $(\mathrm{OR}=1.037$, $95 \% \mathrm{CI} 1.027-1.046)$, is a male ( $\mathrm{OR}=1.589,95 \% \mathrm{CI} 1.024-2.464)$, and has less education $(\mathrm{OR}=2.381,95 \% \mathrm{CI} 1.715-3.311)$. Inadequate storage decreases with the presence of children at home $(\mathrm{OR}=0.314,95 \% \mathrm{CI} 0.225-0.439)$.

The results of multiple logistic regression analysis (Table 3 ) showed that independent factors increasing the risk of inadequate storage are: person responsible for the medications were male (adjusted OR $=1.729,95 \% \mathrm{CI} 1.087-2.752, \mathrm{p}=0.02$ ), of older age (adjusted OR $=1.029$, 95\% CI 1.016-1.042, $\mathrm{p}<0.001$ ), presence of expired medications in the household (adjusted $\mathrm{OR}=2.963,95 \% \mathrm{CI} 1.046-8.397, \mathrm{p}=0.04$ ), and household with no children (adjusted OR $=2.088$, $95 \%$ CI 1.416-3.077, $\mathrm{p}<0.01)$. Nearly reaching statistical significance was a lower household income (adjusted OR $=1.217,95 \%$ CI 0.908-1.506, $\mathrm{p}=0.073$ ).

Table 1. Basic characteristics of subjects, households and stored medicines.

\begin{tabular}{lcc}
\hline Characteristic & \multicolumn{2}{c}{ Values } \\
\hline Person in charge of medicines & 54.9 & 19.2 \\
Age in years (mean, SD) & 190 & 71.2 \\
Female gender (n, \%) & 166 & 62.2 \\
Education > elementary school (n, \%) & 1.7 & 0.9 \\
Household & 3.3 & 1.4 \\
Income in MW (mean, SD) & 94 & 35.2 \\
Residents per household (mean, SD) & & \\
Households with children (n, \%) & 3.7 & 77.2 \\
Medicines & 620 & 66.8 \\
Number of stored medicines (mean, SD) & 536 & 8.4 \\
Solid and semi-solid formulations (n, \%) & 308 & 2.4 \\
Absence of secondary packaging (n, \%) & 19 & \\
Not used in the previous week (n, \%) & & \\
Expired validity (n, \%) & & \\
\hline
\end{tabular}

MW: minimum wage (R\$678.00 equivalent to approximately US\$340.00 at the time of data acquisition) 
Table 2. Characteristics of home storage of medications and methods of disposal.

\begin{tabular}{lcc}
\hline Characteristic & Values & $\mathbf{9 5 \%} \mathbf{C l}$ \\
\hline Inadequate storage $(\mathrm{n}, \%)$ & $203(76.0 \%)$ & $70.5-81.0$ \\
Direct exposure of sunlight $(\mathrm{n}, \%)$ & $29(10.9 \%)$ & $7.4-15.2$ \\
Contamination with dust $(\mathrm{n}, \%)$ & $63(23.6 \%)$ & $18.6-29.1$ \\
Within the reach of children $(\mathrm{n}, \%)$ & $203(76.0 \%)$ & $70.5-81.0$ \\
Room temperature $\left({ }^{\circ} \mathrm{F}, \mathrm{SD}\right)$ & $86.7(36.1)$ & \\
Room temperature $\left({ }^{\circ} \mathrm{C}, \mathrm{SD}\right)$ & $30.4(2.3)$ & \\
Relative humidity $(\%)$ & $50.4(7.3)$ & \\
Predominant storage room $(\mathrm{n}, \%)$ & & $45.5-57.8$ \\
$\quad$ Kitchen & $141(52.9 \%)$ & $4.3-10.9$ \\
$\quad$ Living room & $19(7.1 \%)$ & $27.7-39.3$ \\
$\quad$ Bedroom & $89(33.2 \%)$ & $4.0-10.5$ \\
$\quad$ Others & $18(6.8 \%)$ & \\
Medicine disposal $(\mathrm{n}, \%)$ & & $88.2-95.1$ \\
$\quad$ Home garbage or public sewage system & $246(92.1 \%)$ & $4.9-11.8$ \\
$\quad$ Returned to health facilities & $21(7.9 \%)$ & \\
\hline
\end{tabular}

Table 3. Univariate and multivariate analyses of factors associated with inadequate home storage of medicines.

\begin{tabular}{|c|c|c|c|c|}
\hline \multirow{2}{*}{ Characteristic } & \multicolumn{2}{|l|}{ Univariate } & \multicolumn{2}{|l|}{ Multivariate } \\
\hline & Odds ratio $(95 \% \mathrm{Cl})$ & $\mathbf{p}$ & Odds ratio $(95 \% \mathrm{Cl})$ & $\mathbf{p}$ \\
\hline \multicolumn{5}{|l|}{ Person in charge of medicines } \\
\hline Age in years & $1.037(1.027-1.046)$ & $<0.001$ & $1.029(1.016-1.042)$ & $<0.001$ \\
\hline Male gender & $1.589(1.024-2.464)$ & 0.039 & $1.729(1.087-2.752)$ & 0.021 \\
\hline Education > elementary school & $0.420(0.302-0.583)$ & $<0.001$ & $0.998(0.652-1.529)$ & 0.994 \\
\hline \multicolumn{5}{|l|}{ Household } \\
\hline Income in MW & $0.833(0.693-1.000)$ & 0.051 & $0.822(0.664-1.018)$ & 0.073 \\
\hline Residents per household & $1.012(0.960-1.067)$ & 0.656 & & \\
\hline Households with children & $0.314(0.225-0.439)$ & $<0.001$ & $0.479(0.325-0.706)$ & $<0.001$ \\
\hline \multicolumn{5}{|l|}{ Medicines } \\
\hline Number of stored medicines & $0.974(0.903-1.052)$ & 0.504 & & \\
\hline Liquid formulations & $0.742(0.511-1.076)$ & 0.115 & & \\
\hline No secondary packaging & $1.311(0.936-1.837)$ & 0.115 & & \\
\hline Not used in the previous week & $1.325(0.953-1.840)$ & 0.094 & $0.813(0.561-1.180)$ & 0.277 \\
\hline Expired validity & $2.355(0.933-5.942)$ & 0.070 & $2.963(1.046-8.397)$ & 0.041 \\
\hline
\end{tabular}

MW: minimum wage (R\$678.00 equivalent to approximately US\$340.00 at the time of data acquisition)

\section{DISCUSSION}

This study is relevant to healthcare professionals and to the community in general because it sheds some light into the modalities of home storage of medicinal products and the extent of inadequate storage, and identifies some key factors for an increased risk of inadequate storage. Our main findings were that medications were stored inadequately in the majority of homes, that the most frequent problem was storage of medications within reach of the children, and that the risk of inadequate storage was greater when home medicine organizers were male, of advanced age, and when there are out of date medicines. In contrast, the presence of children at home decreases the risk of inadequate storage.

Increased consumption increases the possibility of accumulating medications at home, both those prescribed for long-term treatment and those prescribed for short time administration². Nevertheless, regardless of the purpose of the treatment, the adequacy of medicine home storage is influenced by the characteristics of the medicines and the characteristics of the 
subjects. For example, when improperly packaged, pharmaceuticals can lose effectiveness or toxicity can increase ${ }^{6}$. Chemical, physical, and microbiological changes may be caused by extremes of temperature, humidity, and light, especially if the medicinal product is kept out of its original packaging, or stored near food and chemicals ${ }^{9}$. Environmental conditions may also play a key role. Thus, in a first analysis, the correct way to store medications should primarily consider their protection from these environmental factors, in order to maintain their effectiveness and safety. With regard to characteristics related to the subject, accumulation of medications at home favors administration errors and decreases medication adherence, especially in older adults with visual and cognitive impairment ${ }^{3}$. Greater availability of medications at home may promote self-medication by, eventually, promoting the utilization of leftovers from previous treatments and of over-the-counter medicines for treating symptoms that had been previously experienced, thus reducing the search for healthcare consultations ${ }^{1,21}$.

The storage location in the household also influences the adequacy of storage. Storing medicines in places easily accessible is a risk factor for the occurrence of accidental poisoning in children and suicide attempts ${ }^{10,11}$. Sometimes a solution to one issue has untoward consequences. For example, in Belgium, it is common to use home medication cabinets, which adequately maintain the chemical integrity of medicines, but these may also facilitate the access by children and adolescents ${ }^{1}$. The storage of medicines on top of the kitchen refrigerator is common practice in some Middle Eastern countries, which, while preventing the access of children to medicines, also exposes medications to excess heat generated by the equipment and to soiling during the preparation of food $\mathrm{d}^{14,16}$.

Therefore, notwithstanding the potentially hazardous consequences to individuals, especially children and to patients, and of being a public health problem, there is no consensus on what would be considered adequate home storage of medications. In our study, we followed the guidelines from regulatory agencies to define the criteria of adequate home storage of medications - out of reach of children and protected from heat, humidity, light, and dust ${ }^{22,23}$. We also attempted to be systematic and objective in other aspects of the methodology of the study. For example, during the execution of the work, the medications and their storage were directly observed in their actual location at the time of the interview, and the respondent was the family member responsible for keeping and organizing medicines at home.

Inadequate storage was associated with age in our data. Advanced age, with its consequent increase in the prevalence of chronic diseases, is strongly associated with the number of medications administered daily ${ }^{24}$ and the quantities stored at home ${ }^{3}$. Large amounts of medications at home increase the risk of administration errors, adverse reactions, medication interactions ${ }^{4}$, and the use of expired medications. In addition, older people often have sight, motor, and memory limitatios ${ }^{25}$, which may promote the placement of medications in easily accessible places and dispersed inside the house. This disorganization of medications, with multiple storage locations and frequent absence of the packaging and the summary of product characteristics, may cause lower medication adherence ${ }^{5}$.

Our data indicate that the organization of medications by male subjects is strongly associated with inadequate storage. The responsibility for medication management at home falling into women is a common pattern in many parts of the world. In Australia, women tend to buy and store medications at home more often than men ${ }^{3}$. A study in Uganda showed that women are more willing to talk about medicines and are traditionally responsible for the health of children within the family ${ }^{26}$, a similar finding was seen in a Greek study ${ }^{17}$.

A positive aspect revealed in our study is that the presence of children in households is generally associated with greater care in medication storage. Medication stored within reach of children is an important risk factor for serious accidental poisoning ${ }^{11}$. In Turkey, between 1985 and 2008, 65\% of cases of domestic poisoning in children was associated with medications ${ }^{10}$. The same study showed that, in 2,251 cases of poisoning in children, $82 \%$ was due to easy access to the medication at home. The prevalence of homes with medicines within 
the reach of children in our sample was high (76\%), well above that of United States (30\%) Belgian (33\%) $)^{1}$, and Serbian (20\%) households ${ }^{19}$.

The disposal of medications in the home waste and the sewage system was common. Lack of adequate processing of medication leftovers carries the risk of environmental contamination ${ }^{15}$. In the United States, a significant amount of water sources for human consumption contain traces of medications? ${ }^{7}$. This form of disposal is common in many countries ${ }^{15,17,19}$.

The social and economic characteristics of the population in our study reduce the scope of possible generalizations because the prevalence of inadequate medicine home storage is likely to be closely linked to economic development. For example, in the United State, there is a significant accumulation of medications in households, reflecting excessive consumption made possible by economic wealth ${ }^{2}$. In contrast, in Uganda, after two decades of civil war, only $35 \%$ of households store medications ${ }^{26}$. Our study has other limitations. Regional characteristics may make it difficult to generalize the findings to other major cities and beyond the Brazilian Northeast. A consensual definition of adequate medicine home storage is not available, but we tried to overcome this problem by adopting a definition based on the guidelines of international organizations. Nevertheless, methodological aspects of our study that contribute to the validity of the results include being a population study based on a probability sample, data obtained by direct interview without previous appointment, and direct observation of the storage location.

Our results address a subject relevant but poorly understood by health professionals. This survey based on a probability sample of households has shown inadequate storage of medicines in the majority of homes, most often because medications are kept within reach of children. The study identified variables that may signal inadequate home storage of medicines, namely the keeper of medicines at home is male and of older age, the lack of children in the household, and the presence of expired medications. Almost all medications are disposed of through domestic waste or the public sewage system. These results emphasize the need for prescribing physicians and pharmacists to inform patients on how to properly store medications at home, especially those who have any of the risk factors here identified.

\section{REFERENCES}

1. De Bolle L, Mehuys E, Adriaens E, Remon JP, Van Bortel L, Christiaens T. Home medication cabinets and self-medication: a source of potential health threats? Ann Pharmacother. 2008;42(4):572-9. https://doi.org/10.1345/aph.1K533

2. Garey KW, Johle ML, Behrman K, Neuhauser MM. Economic consequences of unused medications in Houston, Texas. Ann Pharmacother. 2004;38(7-8):1165-8. https://doi.org/10.1345/aph.1D619

3. Sorensen L, Stokes JA, Purdie DM, Woodward M, Roberts MS. Medication management at home: medication-related risk factors associated with poor health outcomes. Age Ageing. 2005;34(6):626-32. https://doi.org/10.1093/ageing/afi202

4. Wasserfallen JB, Bourgeois R, Büla C, Yersin B, Buclin T. Composition and cost of drugs stored at home by elderly patients. Ann Pharmacother. 2003;37(5):731-7.

5. Holloway K, Mathai E, Gray A; Community-Based Surveillance of Antimicrobial Use and Resistance in Resource-Constrained Settings Project Group. Surveillance of community antimicrobial use in resource-constrained settings: experience from five pilot projects. Trop Med Int Health. 2011;16(2):152-61. https://doi.org/10.1111/j.1365-3156.2010.02695.x

6. Gracia-Vásquez SL, Ramírez-Lara E, Camacho-Mora IA, Cantú-Cárdenas LG, Gracia-Vásquez YA, Esquivel-Ferriño PC, et al. An analysis of unused and expired medications in Mexican households. Int J Clin Pharm. 2014;37(1):121-6. https://doi.org/10.1007/s11096-014-0048-1

7. Benotti MJ, Trenholm RA, Vanderford BJ, Holady JC, Stanford BD, Snyder SA. Pharmaceuticals and endocrine disrupting compounds in U.S. drinking water. Environ Sci Technol. 2009;43(3):597-603. https://doi.org/10.1021/es801845a

8. Frimpter GW, Timpanelli AE, Eisenmenger WJ, Stein HS, Ehrlich LI. Reversible "Fanconi syndrome" caused by degraded tetracycline. JAMA. 1963;184(2):111-3. https://doi.org/10.1001/jama.1963.03700150065010 
9. Stanisz B, Regulska K. Kinetics of degradation of imidapril hydrochloride in finished dosage formulations. Acta Pol Pharm. 2013 [cited 2017 Jun 30];70(4):737-42. Available from: http://www.ptfarm.pl/pub/File/Acta_Poloniae/2013/4/737.pdf

10. Özdemi R, Bayrakcı B, Teksam Ö, Yalçın B, Kale G. Thirty-three-year experience on childhood poisoning. Turk J Pediatr. 2012 [cited 2017 Jun 30];54(3):251-9. Available from: http://www.turkishjournalpediatrics.org/uploads/pdf_TJP_1059.pdf

11. Budnitz DS, Salis S. Preventing medication overdoses in young children: an opportunity for harm elimination. Pediatrics. 2011;127(6):e1597-9. https://doi.org/10.1542/peds.2011-0926

12. Arrais PS, Brito LL, Barreto ML, Coelho HL. [Prevalence and determinants of medicines consumption in Fortaleza, Ceará, Brazil]. Cad Saude Publica. 2005;21(6):1737-46. Portuguese. https://doi.org/10.1590/S0102-311X2005000600021

13. Seehusen DA, Edwards J. Patient practices and beliefs concerning disposal of medications. J Am Board Fam Med. 2006;19(6):542-7. https://doi.org/10.3122/jabfm.19.6.542

14. Sharif SI, Abduelkarem AR, Bustami HA, Haddad LI, Khalil DS. Trends of home drug storage and use in different regions across the northern United Arab Emirates. Med Princ Pract. 2010;19(5):355-8. https://doi.org/10.1159/000316372

15. Wieczorkiewicz SM, Kassamali Z, Danziger LH. Behind closed doors: medication storage and disposal in the home. Ann Pharmacother. 2013;47(4):482-9. https://doi.org/10.1345/aph.1R706

16. Kheir N, El Hajj MS, Wilbur K, Kaissi RML, Yousif A. An exploratory study on medications in Qatar homes. Drug Health Patient Saf. 2011;3:99-106. https://doi.org/10.2147/DHPS.S25372

17. Tsiligianni IG, Delgatty C, Alegakis A, Lionis C. A household survey on the extent of home medication storage. A cross-sectional study from rural Crete, Greece. Eur J Gen Pract. 2012;18(1):3-8. https://doi.org/10.3109/13814788.2011.604674

18. Mastroianni PC, Lucchetta RC, Sarra JR, Galduróz JCF. [Household storage and use of medications in a population served by the family health strategy in Brazil]. Rev Panam Salud Publica. 2011;29(5):358-64. Portuguese. https://doi.org/10.1590/S1020-49892011000500009

19. Kusturica MP, Sabo A, Tomic Z, Horvat O, Šolak Z. Storage and disposal of unused medications: knowledge, behavior, and attitudes among Serbian people. Int J Clin Pharm. 2012;34(4):604-10. https://doi.org/10.1007/s11096-012-9652-0

20. Ribeiro MA, Heineck I. Drug storage at home in the community assisted by the Family Health Programme in Ibiá, MG, Brazil. Saude Soc. 2010;19(3):653-63. https://doi.org/10.1590/S0104-12902010000300016

21. Tourinho FSV, Bucaretchi F, Stephan C, Cordeiro R. Home medicine chests and their relationship with self-medication in children and adolescents. J Pediatr (Rio J). 2008;84(5):416-22. https://doi.org/10.1590/S0021-75572008000600007

22. World Health Organization. Annex 9. Guide to good storage practices for pharmaceuticals. Geneva; 2003 [cited 2017 Jun 30]. (WHO Technical Report Series, 908). Available from: http://www.who.int/medicines/areas/quality_safety/quality_assurance/ GuideGoodStoragePracticesTRS908Annex9.pdf

23. Royal Pharmaceutical Social of Great Britain. The handling of medicines in social care. London; 2007. p.7-32.

24. Gellad WF, Grenard JL, Marcum ZA. A systematic review of barriers to medication adherence in the elderly: looking beyond cost and regimen complexity. Am J Geriatr Pharmacother. 2011;9(1):11-23. https://doi.org/10.1016/j.amjopharm.2011.02.004

25. Jin J, Sklar GE, Min Sen Oh V, Chuen Li S. Factors affecting therapeutic compliance: a review from the patient's perspective. Ther Clin Risk Manag. 2008;4(1):269-86. https://doi.org/10.2147/TCRM.S1458

26. Ocan M, Bbosa GS, Waako P, Ogwal-Okeng J, Obua C. Factors predicting home storage of medicines in Northern Uganda. BMC Public Health. 2014;14:650. https://doi.org/10.1186/1471-2458-14-650

Authors' Contribution: Conception and planning of the study: RRM, YMCO and ADF. Data analysis and interpretation: RRM and AGO. Writing of the manuscript: RRM, ADF, YMCO and RSD. All authors approved the final version of the manuscript.

Conflict of Interest: The authors declare no conflict of interest. 